\title{
Lakrimal Kese Tümörleri Tedavisi İçin VMAT ve IMRT Planlama Tekniklerinin Karşılaştırılması
}

\author{
İsmail Serdar Sürenkök $\odot$, Melih Uluer $\odot$, Burak Başlangıç®), Emre Tahberer $\odot$
}

Acıbadem Eskişehir Hastanesi, Radyoterapi, Eskişehir, Türkiye

İsmail Serdar Sürenkök, Prof. Dr. Melih Uluer, Medikal Fizik Uzm. Burak Başlangıç, Medikal Fizik Uzm. Emre Tahberer, Uzm. Dr.

Iletişim:

Prof. Dr. İsmail Serdar Sürenkök

Acıbadem Eskişehir Hastanesi, Radyoterapi,

Eskișehir, Türkiye

Tel: +902222144934

E-Posta: ismail.surenkok@acibadem.com.tr

Gönderilme Tarihi : 08 Aralık 2017

Revizyon Tarihi : 160cak 2018

Kabul Tarihi : : 210 cak 2018
ÖZET

Lakrimal kese tümörleri az görülmesine karşın; lokal invazyon, hastalığın tekrarlama ve metastaz yapma potansiyeli yüksektir. Bu tümörlerin nadir görülmesi nedeniyle mevcut tedavi uygulamaları için karar verme çok az sayıdaki olgu raporuna göre yapılmaktadır. Bu tümörlerin büyük kısmı epitelyal kökenlidir. En belirgin semptomları epifora ve orbital medial kantus bölgesinde kitledir. Bu nedenle dakriyosistit ile karışabilir. Tanıda kapsamlı oftalmik muayene ve görüntüleme yöntemleri oldukça önemlidir. Hastalığın primer tedavisi cerrahi olup; adjuvan tedavi olarak radyoterapi ve/veya kemoterapi uygulanabilir. Çalışmamızda simultane integre boost (SIB) tekniği kullanılarak homojen doz dağılımı ve doz gradientini karşılaştırmak, ayrıca belirli kritik organların dozlarını değerlendirmek amacıyla Hacimsel Yoğunluk Ayarlı Ark Tedavisi (VMAT) ve Yoğunluk Ayarlı Radyoterapi (IMRT) planları karşılaştırılmıştır.

Anahtar sözcükler : Lakrimal kese tümörleri, VMAT, IMRT

\section{COMPARISON OF VMAT AND IMRT PLANNING TECHNIQUES FOR LACRIMAL SAC TUMOR TREATMENT}

\section{ABSTRACT}

Although lacrimal sac tumors are rarely seen, they have a high potential for local invasion, local recurrence, and distant metastasis. Given their rarity, decision making for the treatment of these tumors is based on very few case reports. Majority of these tumors are of epithelial origin. Most prominent symptoms are epiphora and mass in the medial canthus region. For this reason, it may be confused with dacryocystitis. Thorough ophthalmic examination and imaging are very important for diagnosis. Primary treatment of the disease is surgery, radiotherapy and/or chemotherapy may be used as adjuvant therapy. In our study, we compared Volumetric Modulated Arc Therapy (VMAT) and Intensity Modulated Radiation Therapy (IMRT) plans with the aim of comparing the homogeneous dose distribution and dose gradient using the Simultaneous Integrated Boost (SIB) technique and also assessing the dose of certain critical organs.

Keywords: Lacrimal sac tumors, VMAT, IMRT

akrimal keseden köken alan tümörler az görülmesine karşın; potansiyel olarak hayati tehlike oluştururlar. 1930'lu yıllardan günümüze kadar literatürde 775 olgu bildirilmiştir. Tümörlerin \%50'sinden fazlası malign olup, lokal invazyon ve tekrarlama oranları yüksektir (1). Lokal nüks, metastaz ve mortalite oranları tümörün evresi ve büyüklüğü ile ilişkilidir (2). Lakrimal kese tümörleri histopatolojik olarak epitelyal, mezenşimal, lenfoproliferatif ve melanositik olarak 4 farklı grup altında sınıflandırılır. Malign tümörlerin \%90'ı epitelyal kökenlidir. Lakrimal kese tümörlerinde tedavilere rağmen $\% 50^{\prime} l i k$ nüks oranı ile birlikte mortalite oranları da yüksektir. 
Sıklıkla komşu yapılara invazyon görülür. Lenfatik yol ile preauriküler, submandibular ve servikal lenf nodlarına metastaz yaparlar. İleri evre olgularda metastazların en sık görüldüğü yerler akciğer ve özefagustur $(3,4,5,6)$.

Orbital medial kantus bölgesinde kitle ve epifora en belirgin semptomlardır. Bu nedenle dakriyosistit ile karışabilir. Lakrimal kesede kitle ve epifora yakınması olan olgularda ayrıntılı oftalmik muayane yapılmalıdır (2). Görüntüleme yöntemleri, lakrimal kese tümörlerinin tanısında önemli yer tutar. Orbital ve paranasal sinüs bilgisayarlı tomografisi (BT) kitle lezyonunun paranasal sinüsler dahil kemik yapılara invazyonu, kontrastlı T1 ve T2 ağırlıklı manyetik rezonans görüntüleme (MRG) lezyonun kistik/inflamatuvar ya da solid kitle ile çevre yumuşak dokulara invazyonu hakkında önemli katkılar sağlar. Histopatolojik tanıda olası kanama, enfeksiyon ve yetersiz biyopsi riski nedeni ile ince iğne aspirasyon biyopsi yerine insizyonel biyopsi tercih edilir $(4,5,8,9)$.

Lakrimal kese tümörlerinin tedavisi; tümörün histopatolojisi, büyüklüğü ve çevre dokulara yayılımına bağlı olarak değişir. Lakrimal keseye sınırlı tümörlerde dakriyosistektomi yeterli olurken lokal invazyon yapmış tümörlerde komşu orbital ve nazal duvarlar ile birlikte lakrimal drenaj sistemininde rezeksiyonu gereklidir. Lakrimal drenaj sistemi dışında tümör yayılımına ait bulgular varsa orbital ekzantrasyon, lateral rinotomi ve servikal lenf nodu diseksiyonu gibi radikal girişimler yapılabilir $(3,4,5,7,10,11)$.

Radyoterapi postoperatif dönemde kemik tutulumu, lenfatik invazyon ya da cerrahi sınırda tümör devamlılığı olduğu durumlarda endikedir. Önerilen toplam doz 6000 ile 7000 cGy arasında değişmektedir. Kemoterapi metastatik hastalık veya tümör tekrarlama riskini en aza indirmek amacıyla uygulanır $(3,4,5,7,12)$.

Olgumuz olan 68 yaş kadın hastamızda, 2015 yılında burun tıkanıklığı, sol göz iç kısmında ağıı yakınması ile başvurduğu merkezde yapılan muayene ve radyolojik çalışmalar sonucunda, sol lakrimal kese lokalizasyonunda başlayan sol orta nazal konka ve orbital yağ doku içerisine uzanan $23 \times 17 \times 25 \mathrm{~mm}$ boyutlarında kemik yapılara destrüksiyona neden olmayan kitle lezyonu saptanmıştır. Yapılan biopsi sonucunda bazal hücreli adenokarsinom tanısı konmuştur. Daha sonra başka bir merkezde kitle eksizyonu ile birlikte parsiyel ethmoidektomi, nasal kemik eksizyonu, maksiller sinüs medial duvar eksizyonu operasyonu uygulanmıştır. Postoperatif patolojisi düşük grade'li adenokarsinoma olarak rapor edilmiştir. Hastanın 2017 yılı Haziran ayında sol göz iç kısmında ağrı ve şişlik yakınması üzerine yapılan MRG'de; sol göz iç kontrol bölgede kitle lezyonu saptanmıştır. Yapılan biopsi sonucu düşük grade'li adenokarsinom olarak rapor edilmiştir. Hasta eksternal radyoterapi için merkezimize başvurmuştur.

\section{Yöntem gereçler}

Tedavi ve planlama için hastaya termoplastik maske uygulanarak tedavi kesinliği için baş hareketi kısıtlanmıştır. Planlama için BT görüntüleri 2 mm'lik kesitler halinde elde edilip kontrastlı T1 ağırlıkı MRG ile füzyon edilerek hedef ve kritik organ çizimleri için uygun hale getirilmiştir. Kitle lezyonu gross target volume (GTV) olarak tanımlanıp $2 \mathrm{~mm}$ marj verilerek planning target volume

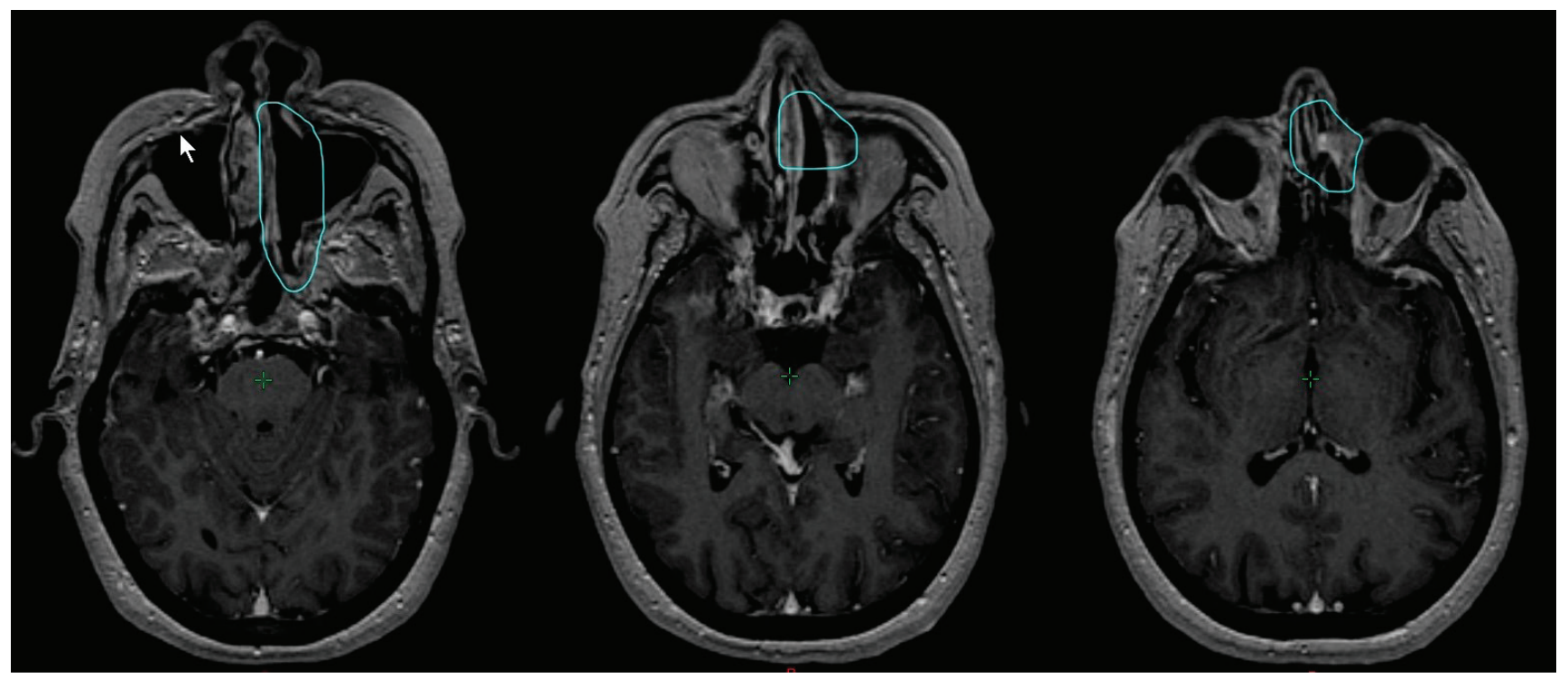

Şekil. 1 MRG füzyonlu BT görüntüleri ve hedef yerleşimi 


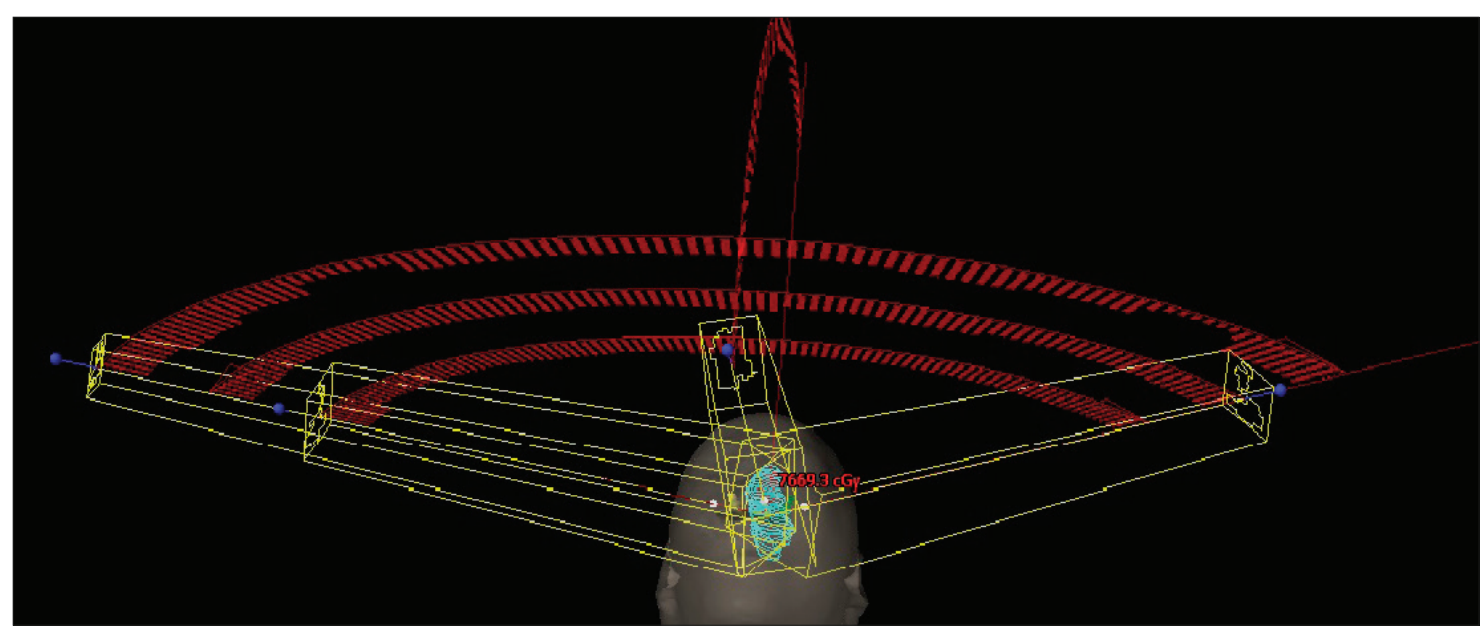

Şekil 2. VMAT yarım ark açıları

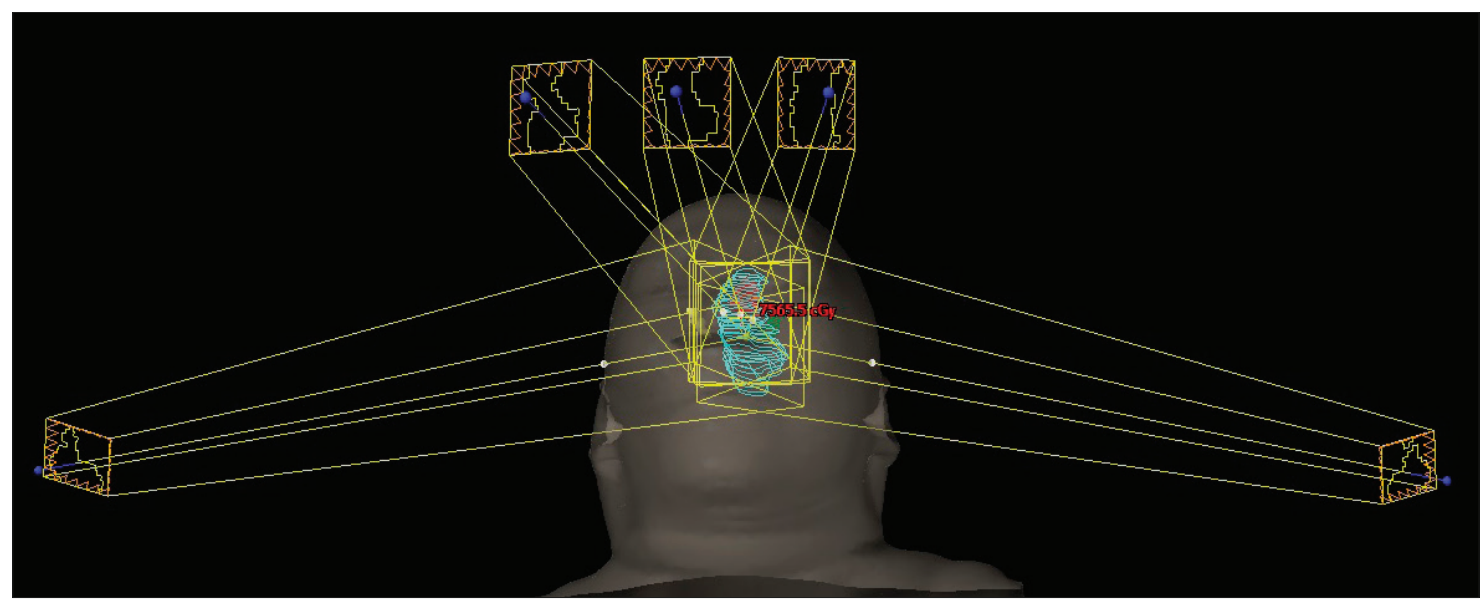

Şekil 3. IMRT 5 alan açıları

(PTV70) oluşturulmuştur. Daha önce opere edilen bölge clinical target volume 60 (CTV60) olarak belirlenip 3mm marj verilerek PTV60 oluşturulmuştur. Kitle lezyonunun lokalizasyonuna bağlı olarak krtik organ olarak; gözler, lensler, optik sinirler, beyin, beyin sapı ve lakrimal kese konturlanmıştır. Planlamar, VMAT ve IMRT teknikleri ile (SIB) uygulanarak kitle lezyonuna (PTV70) 212cGy/33gün fraksiyonasyon dozlarında toplam 6996 cGy, PTV60 olarak tanımlanan bölgeye181.8cGy/33gün fraksiyonasyon dozlarında toplam 6000 cGy eksternal radyoterapi uygulanmıştır. Planların giriş açıları ve alan sayıları, tümör yerleşimine göre doz sarımı ve kritik organların korunması gözetilerek belirlenmiştir. VMAT planı için masa açılı 4 yarım ark (300 $-50^{\circ}$ arası 2 kez saat yönüne, kolimatör $10^{\circ}$ ve $90^{\circ}, 1$ kez saat yönü tersine kolimatör, $350^{\circ} 3$ yarım ark ve masa90 $957-100^{\circ}$ saat yönüne, kolimatör $10^{\circ}, 1$ yarım ark), IMRT planı için $0^{\circ}, 10^{\circ}, 350^{\circ}, 130^{\circ}, 240^{\circ}$ açılar kullanılarak planlar oluş̧turulmuştur.
Planlar, homojenite indeks (HI):(D2\%-D98\%)/D50\% (13), monitor unit (MU) yüksek ve orta doz saçılmalarına göre değerlendirilmiştir. Tümör yerleşimine göre belirlenen kritik organlar gözler, lensler, optik sinirler, sağ lakrimal kese için aldığı maksimum doz (dmaks.) ve beyin ortalama dozu (dort.) VMAT ve IMRT için karşılatırılmıştır.

\section{Bulgular}

Planlar incelendiğinde PTV70 HI'i VMAT için 0,118, IMRT için 0,074 değerlerine sahiptir. Planların yüksek doz dağılımlarını ifade eden \%95 ve \%80'lik izodoz hacimleri için sırası ile $\% \Delta 8,71$ ve $\% \Delta 22$, orta doz dağılımlarını ifade eden $\% 50$ ve $\% 20$ lik izodoz hacimleri için ise $\% \Delta 70,9$ ve $\% \Delta 64,6$ ile VMAT planları IMRT plnalarına üstünlük sağlamıştır.

VMAT planları 4 yarım ark için toplam 299 MU'ya sahip iken 5 alan IMRT planı için 835 MU olarak hesaplanmış ve VMAT planı IMRT planından \%36 daha düşük MU değeri 
ortaya koymuştur. İncelenen kritik organlardan yalnızca sol optik sinir, lens, sağ lakrimal kese ve beyin sapı dmaks değerleri IMRT planlarında daha iyi iken diğer kritik organlar VMAT planları lehine sonuç vermiştir.

Tablo 1. Yüksek ve orta izodoz hacimleri

\begin{tabular}{lccc} 
izodaz & VMAT (cc) & IMRT (cc) & $\% \mathbf{\Delta}$ \\
\hline$\% 95$ & 6,31 & 6,86 & 8,71 \\
$\% 80$ & 63,56 & 77,56 & 22 \\
$\% 50$ & 127,26 & 217,58 & 70,9 \\
$\% 20$ & 362,23 & 596,27 & 64,6
\end{tabular}

Tablo 2. VMAT IMRT kritik organ dozları

\begin{tabular}{lccc} 
Kritik Organlar & VMAT (cGy) & IMRT (cGy) & $\% \mathbf{\Delta}$ \\
\hline Sağ göz Dmaks. & 1935,3 & 3253,6 & 68,1 \\
Sol göz Dmaks. & 3896,1 & 4948 & 27 \\
Sağ lens Dmaks. & 457,5 & 592,2 & 29,5 \\
Sol lens Dmaks. & 2839,6 & $1258,8^{*}$ & 225,57 \\
Sol optik sinir Dmaks. & 3425,4 & $2894,5^{\star}$ & 18,3 \\
Sağ optik sinir Dmaks. & 2031,5 & 2720,5 & 34 \\
Sağ lakrimal kese Dmaks. & 5606,2 & $4200,8^{*}$ & 33,4 \\
Beyin sapı Dmaks. & 2616,2 & $1462,2^{\star}$ & 78,9 \\
Beyin Dort. & 615,1 & 694,8 & 13
\end{tabular}

\section{Tartışma ve sonuçlar}

VMAT son yıllarda yaygın olarak kullanılan ve IMRT ile kıyaslanabilen plan kalitesi kritik organ koruması potansiyeline sahip bir planlama tekniğidir. Bu çalışmada planlar; HI, yüksek ve orta izodoz hacimleri, MU ve hedef komşuluğunda bulunan kritik organlar bakımından karşılaştırılmıştır. HI değerleri benzer değerlere sahip olmakla birlikte
IMRT planlarındaki belirli açılarda, hedefin değişen çok yapraklı kolimatör (ÇYK) hızları ve harekete bağlı küçük alanlar ile oluşan yüksek doz grandyenti VMAT planlarına göre daha iyi HI değerlerine sahip olmasını sağlayabilmektedir. Bahsedilen özellikler incelenen diğer parametre MU için ise VMAT planlarını öne çıkartmaktadır. VMAT planları IMRT planlarının aksine genellikle gantry rotasyonu içerisinde geniş alanlar ile ışınlama yaparken, IMRT planları ile benzer hedef sarımı için daha az MU'e ihtiyaç duyar (14). Çalışmada elde edilen MU değerleri literatür ile uyumludur (15). VMAT tekniğinin gantry rotasyonu ve ÇYK hareketlerine bağıı olarak IMRT planlarına göre daha konformal planlar ortaya çıkarabilmektedir (16). Çalışmada incelenen yüksek ve orta izodoz hacimleri, VMAT planındaki 4 yarım ark'tan elde edilen daha fazla açıdan optimizasyon yapabilme kapasitesi ile IMRT plana göre daha düşük izodoz hacimlerine sahiptir (15). Elde edilen planlar için kritik organ dozları karşılaştııılığında; beyin sapı, sağ lakrimal kese, sol optik sinir ve lens IMRT planları için daha iyi sonuç vermiştir. IMRT planları incelendiğinde bu kritik organların kullanılan açılara bağlı olarak alan dışı veya ÇYK'lerin altında kaldığı tespit edilmiştir. Periferde bulunan diğer kritik organlar, VMAT tekniği ile daha iyi korunmuştur (17). Çoklu ark, parsiyel ve non koplanar arkların kullanımı ve kritik organ yerleşimine göre alan seçimleri kritik organ dozları düşürmek için kullanılabilir (18).

Çalışmada VMAT ve IMRT planlama teknikleri lakrimal kese tümörleri için benzer hedef sarımlarına sahip olsa da düşük MU değeri, izodoz dağılımları ve kritik organ korunması parametreleri ile VMAT tekniğini öne çıkartmaktadır. VMAT planları klinik olarak ve toplam tedavi süresi için tedavi kalitesi ve hasta konforu açısından yeterli sonuçlara sahiptir.

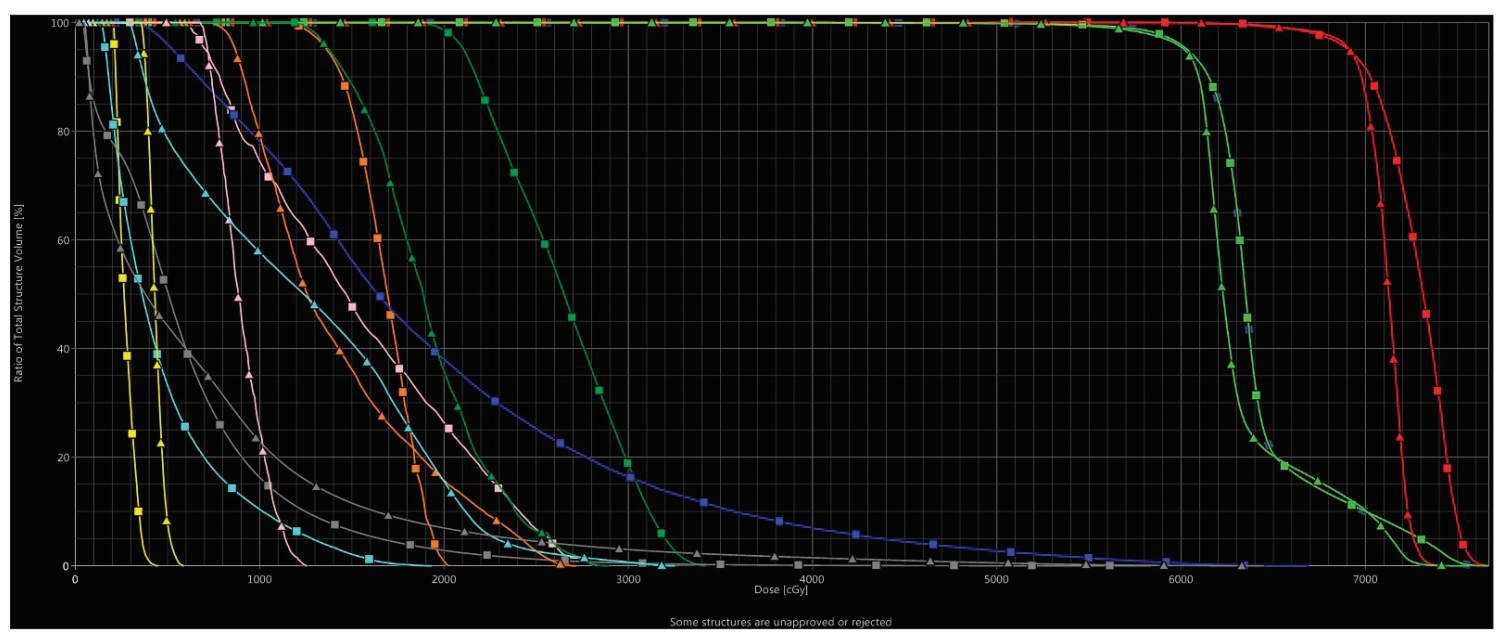

Şekil 4: ^ IMRT, • VMAT planları için doz-hacim histogramı 


\section{Kaynaklar}

1. Krishna Y, Coupland SE. Lacrimal Sac Tumors - A Review. Asia Pac Acad J Ophthalmol (Phila) 2017;6:173-8. [CrossRef]

2. Skinner HD, Garden AS, Rosenthal DI, Ang K, Morrison WH, Esmaeli $B$, et al. Outcomes of malignant tumors of lacrimal apparatus: The University of Texas MD Anderson Cancer Center Experience. Cancer 2011;117:2801-10. [CrossRef]

3. Schenck NL, Ogura JH, Pratt LL. Cancer of lacrimal sac. Presentation of five cases and review of the literature. Ann Otol Rhinol Laryngol 1973;82:153-61. [CrossRef]

4. Parmar DN, Rose GE. Management of lacrimal sac tumours. Eye 2003;17:599-606. [CrossRef]

5. Kim HJ, Shields CL, Langer PD. Lacrimal sac tumors: diagnosis and treatment. In: Black EH, Nesi FA, Gladstone G, Levine MR, Calvano CJ, et al., editors. Smith and Nesi's Ophthalmic Plastic and Reconstructive Surgery, New York; Springer, 2012. pp.609-14.

6. Heindle LM, Jünemann AG, Kruese FE, Holbach LM. Tumors of the lacriamal drainage system. Orbit 2010;29:298-306. [CrossRef]

7. Montelban A, Lietin B, Louvrier C, Russier M, Kemeny JL, Mom T, Gilain L. Malignant Lacrimal sac tumors. Eur Ann Otorhinolaryngol Head and Neck Dis 2010;127:165-72. [CrossRef]

8. Ni C, D'Amico DJ, Fan CQ, Kuo PK. Tumors of the lacrimal sac: a clinicopathological analysis of 82 cases. Int Ophthalmol Clin 1982;22:121-40. [CrossRef]

9. Bi YW, Chen RJ, Li XP. Clinical and pathological analysis of primary lacrimal sac tumors. Zhonghua Yan Ke Za Zhi 2007;43:499-504.

10. Stefanyszyn MA, Hidayat AA, Pe'er JJ, Flanagan JC. Lacrimal sac tumors. Opthalmic Plast Reconstr Surg 1994;10:169-84.
11. Pe'er JJ, Stefanyszyn M, Hidayat AA. Nonepithelial tumors of the lacrimal sac. Am J Ophthalmol 1994;118:650-8.

12. Pe'er J. Lacrimal sac tumors. In: Singh AD, Damato BE, Pe'er J, Perry JD, editors. Clinical Ophthalmic Oncology. Berlin: Springer-Verlag; 2014. pp.115-21.

13. International Commission on Radiation Units and Measurements. (ICRU) Report 83, Prescribing, recording, and reporting intensitymodulated photon-beam radiation therapy (IMRT). J ICRU 2010;10:41-54.

14. Hall EJ. Intensity-modulated radiation therapy, protons, and the risk of second cancers. Int J Radiat Oncol Biol Phys 2006;65:1-7. [CrossRef]

15. Ali MA, Babaiah M, Madhusudhan N, George G. Comparative dosimetric analysis of IMRT and VMAT (RapidArc) in brain, head and neck, breast and prostate malignancies. Int J Cancer Ther Oncol 2015;3:03019. [CrossRef]

16. Otto K. Volumetric modulated arc therapy: IMRT in a single gantry arc. Med Phys 2008;35:310-7. [CrossRef]

17. Wagner $D$, Christiansen $H$, Wolff $H$, Vorwerk $H$. Radiotherapy of malignant gliomas: comparison of volumetric single arc technique (RapidArc), dynamic intensity- modulated technique and 3D conformal technique. Radiother Oncol 2009;93:593-6. [CrossRef]

18. Shaffer R, Nichol AM, Vollans E, Fong M, Nakano S, Moiseenko $\mathrm{V}$, et al. A comparison of volumetric modulated arc therapy and conventional intensity-modulated radiotherapy for frontal and temporal high-grade gliomas. Int J Radiat Oncol Biol Phys 2010;76:1177-84. [CrossRef] 